\title{
Estudo experimental do uso de rebolos convencionais na usinagem do aço VP-50 utilizado na retificação cilíndrica, por meio de diferentes métodos de lubrirrefrigeração
}

\author{
Experimental study of the use of conventional \\ wheels on steel processing VP-50 used in the \\ cylindrical grinding by means of different methods \\ of lubrication and cooling
}

\author{
Marco Antonio dos Anjos ${ }^{1}$, Eduardo Carlos Bianchi ${ }^{1}$, \\ Hamilton José de Mello ${ }^{1,}$ Paulo Roberto de Aguiar ${ }^{1}$, \\ Eduardo Costa Estambasse ${ }^{1,}$ Rodolfo Alexandre Hildebrandt ${ }^{1}$
}

\footnotetext{
${ }^{1}$ Universidade Estadual Paulista - UNESP - Campus de Bauru. Departamento de Engenharia Mecânica, Av. Luiz Edmundo Carrijo Coube, 14-01, Caixa Postal 473, CEP 17033-360, Bauru, SP, Brasil.

e-mail: anjos_marco@hotmail.com; bianchi@feb.unesp.br; hamilton@feb.unesp.br; aguiarpr@feb.unesp.br; eduardoestambasse@yahoo.com.br; hildebrandt@hotmail.com.br
}

\begin{abstract}
RESUMO
A retificação é um processo de usinagem preciso, sendo uma das etapas mais caras na fabricação dos moldes para injeção de termoplásticos. Na retificação o rebolo é a ferramenta abrasiva responsável pela retirada do material. O número de tipos de abrasivos e granulometrias disponíveis são bastante grandes e junto com a quantidade de ligas possíveis, estruturas e durezas, além dos formatos, fazem com que se chegue a um número enorme de produtos. O conhecimento das suas características técnicas, vantagens, defeitos e condições de trabalho são fundamentais para os engenheiros de produto, de processos e, naturalmente, para os gerentes de área industrial, identificarem qual o rebolo mais indicado para realização do processo de retificação. Dentre os aços utilizados na fabricação de moldes para injeção de termoplásticos destaca-se o aço VP-50, o qual foi o aço usado neste experimento, sendo usinado pelo processo de retificação cilíndrica. No processo de retificação, também foi adotado para fins de experimento dois métodos de lubrirrefrigeração, sendo eles o método convencional com lubrirrefrigeração abundante e o MQL que é a técnica com mínima quantidade de lubrirrefrigeração. O objetivo deste trabalho foi analisar de forma comparativa o desempenho de corte executado com três tipos de rebolos convencionais: rebolo de óxido de alumínio branco, rebolo de carbureto de silício verde e rebolo de carbureto de silício preto com óxido de alumínio branco. Os resultados foram analisados e comparados pelas variáveis de saída dos três tipos de rebolos, tipo de refrigeração e espessura equivalente de corte.
\end{abstract}

Palavras-chave: retificação cilíndrica; mínima quantidade de lubrificante; rebolo de óxido de alumínio branco, rebolo de carbureto de silício verde, rebolo de carbureto de silício preto com óxido de alumínio branco.

\section{ABSTRACT}

The grinding is a precise machining process, one of the most expensive steps in the manufacture of in-jection molds for thermoplastic. In grinding the grinding wheel abrasive tool is responsible for removal. The number and types of abrasive grit sizes available are quite large and together with the number of possible alloys, structures and shapes of hardness beyond cause reach an enormous number of products. The knowledge of their technical characteristics, advantages, defects and working conditions are fundamental for product engineers, process and of course to the industrial area managers, which identify the most suitable grinding wheel to perform the grinding process. Among the steels used in the manufacture of molds for ther-moplastic injection highlight the VP-50 steel, which was the steel used in this experiment being machined by the cylindrical grinding process. In the grinding process was also adopted for the purpose of experiment two methods of 
lubrication and cooling them with the conventional method with abundant lubrication and cooling and MQL is the technique with minimal amount of lubrication and cooling. The objective of this study was to analyze comparatively cutting performance, performed with three types of conventional wheels: grinding of white aluminum oxide, green silicon carbide grinding wheel and grinding of black silicon carbide with white aluminum oxide. The results were analyzed and compared by the output variables of the three types of wheels, type of refrigeration and equivalent thickness.

Keywords: cylindrical grinding; minimum amount of lubricant; grindstone white aluminum oxide grinding wheel green silicon carbide, black silicon carbide grinding wheel with white aluminum oxide.

\section{INTRODUÇÃO}

A retificação é provavelmente um dos mais antigos processos de fabricação, e mesmo assim persiste como um moderno componente do sistema de produção, quando é necessária precisão dimensional e geométrica, associada a um excelente acabamento superficial. É caracterizado pelo fato de ser um processo final com baixa taxa de remoção de material, o que a possibilita produzir componentes com grande precisão e qualidade superficial [1].

O processo de retificação é principalmente utilizado para produzir peças de alta qualidade, com grande exatidão e diminuir tolerâncias [2].

A ferramenta de corte utilizada no processo é o rebolo, composto de vários grãos com várias arestas de corte. Devido a essa característica técnica, a retificação comparada aos outros processos de usinagem envolve uma grande quantidade de energia, e parte dessa energia é transformada em calor na zona de corte [3], o que é prejudicial à peça final. Na retificação o rebolo é a ferramenta abrasiva responsável pela retirada do material, os inúmeros e pequenos grãos abrasivos são responsáveis por retirar uma quantidade minúscula de material da peça, possibilitando a obtenção de tolerâncias bastante apertadas. O número de tipos de abrasivos e granulometrias disponíveis são bastante grandes e junto com a quantidade de ligas possíveis, estruturas e durezas, além dos formatos, fazem com que se chegue a um número enorme de produtos. O conhecimento das suas características técnicas, vantagens, defeitos e condições de trabalho são fundamentais para os engenheiros de produto, de processos e, naturalmente, para os gerentes de área industrial, identificarem qual o rebolo mais indicado para realização do processo de retificação. Com tantas características que podem variar, a correta especificação de um rebolo resulta em uma grande gama de opções no momento da escolha do rebolo mais indicado para uma determinada operação, entretanto são poucas as informações que se tem sobre os resultados que podem ser obtidos após o processo de retificação dos aços para moldes de injeção de termoplásticos nesta etapa.

Então, é necessário analisar e comparar resultados obtidos, pelas variáveis de saída, tais como comportamento da força tangencial de corte, rugosidade, emissão acústica, relação G (volume de material removido/volume de material desgastado), microscopia óptica (para verificar se houve dano térmico) e micro dureza. O aço utilizado para análise e obtenção dos resultados foi o aço VP-50.

O aço VP-50 foi desenvolvido pela VILLARES METALS especialmente para fabricação de matrizes para extrusão de termoplásticos e moldes para injeção de termoplásticos. É um aço endurecível por precipitação. Sua usinabilidade elevada permite o fornecimento no estado solubilizado para posterior envelhecimento, ou solubilizado e envelhecido, dispensando o tratamento térmico final.

Na fabricação de moldes e matrizes para injeção de termoplásticos os custos de fabricação são muito elevados, a fração maior destes custos esta nas etapas de usinagem e acabamento por se tratarem de etapas críticas do processo. Por isso é importante a apresentação de dados sobre a usinagem do aço VP-50. Na fase de acabamento, o processo de retificação torna-se a etapa mais cara da usinagem da ferramenta, onde erros não são admissíveis. A escolha do rebolo correto é uma das variáveis que podem garantir o sucesso de todo o processo de fabricação da ferramenta.

\section{O PROCESSO DE RETIFICAÇÃO}

A retificação faz parte do processo de usinagem por abrasão. A usinagem por abrasão é um nome genérico dado ao processo de remoção de material, tanto metal quanto não metal, por meio de pequenas partículas produzidas pelas arestas de cortes de materiais abrasivos [4].

Segundo Malkin [5], o processo de retificação provavelmente seja o processo de modelagem de materiais mais antigo que exista, datando de períodos pré-históricos, onde o homem descobriu como afiar suas ferramentas ao atritá-las em grãos de pedras.

Marinescu et al [2] define retificação como um processo de usinagem que utiliza um rebolo formado 
por grãos abrasivos rotacionando numa alta velocidade para a remoção de material.

A retificação é tradicionalmente o processo de usinagem final numa produção, usado para melhorar superfícies de acabamento e tolerâncias mais finas [5].

Diferente de outros processos de usinagem, como torneamento e fresamento, que apresentam ferramentas de corte definidas, a retificação utiliza-se de ferramentas de corte não definida, ou seja, os grãos abrasivos apresentam arestas de cortes irregulares [6].

No processo de retificação pode-se observar que as operações podem ser agrupadas de acordo com a superfície a ser usinada e com o movimento relativo entre peça e rebolo.
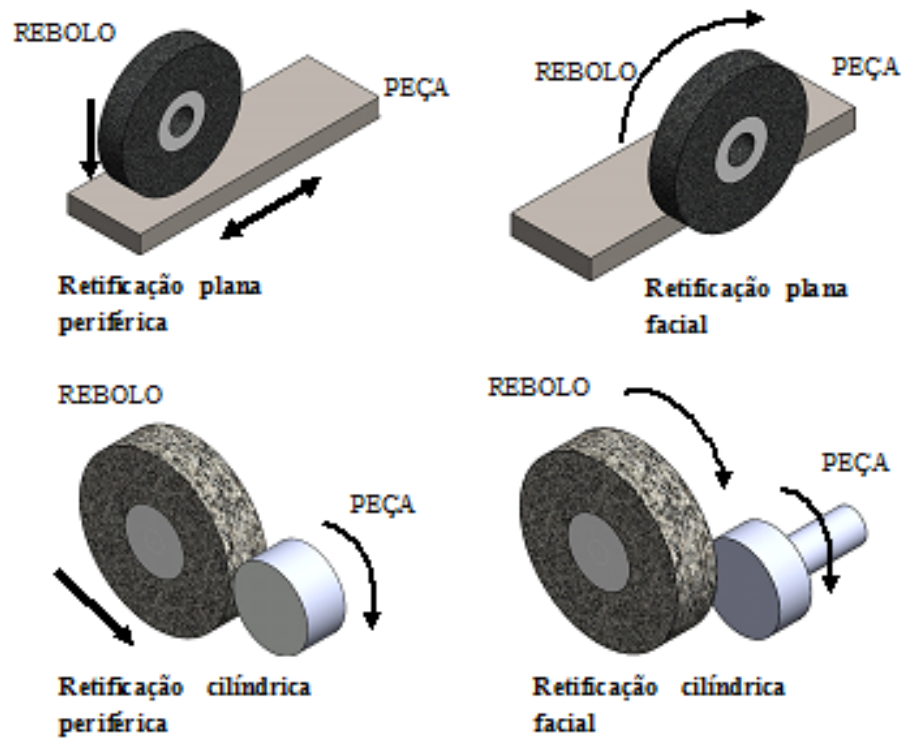

Figura 1: Exemplo das quatro formas básicas de retificação.

É neste processo que serão corrigidos eventuais problemas surgidos em processos anteriores. A retificação é tipicamente um processo de acabamento onde a qualidade é importante e erros custam caro [7].

Segundo Nguyen e Butler [1], apesar de a retificação ter sido um tópico de extensa pesquisa pelos últimos 20 anos, o completo entendimento desta ainda tem que ser alcançado. Isso ocorre, particularmente, pelo fato de que a retificação é um processo estocástico, no qual um grande número de grãos abrasivos de geometria não definida está aleatoriamente atuando na superfície de corte do rebolo (ferramenta de corte utilizada no processo de retificação). A textura final da superfície usinada pode ser considerada como um resultado da somatória da ação individual de cada grão. De fato, a natureza de interação grão/peça é muito complexa e depende de vários fatores que envolvem o rebolo, a peça, a máquina-ferramenta e parâmetros do processo.

\section{O REBOLO}

O rebolo é a ferramenta de revolução utilizada nos processos de retificação. Possui grãos abrasivos ligados por um ligante que formam um corpo abrasivo. Esses grãos formam arestas de corte de geometria não definidas, cujos quais são responsáveis pela remoção do material no processo de retificação [5].

O rebolo pode ser considerado um sistema trifásico, sendo constituído por grãos abrasivos, aglomerantes e poros. Dessa forma, seu desempenho está relacionado ao tipo e ao tamanho do grão abrasivo, as propriedades abrasivas do material e porosidade do conjunto [5].

A fabricação dos rebolos destinados à retificação apresentam diversos tipos de grãos, com diferentes tamanhos e combinados com vários tipos de ligantes com composições distintas [5].

Segundo Cai e Rowe [8] citado por Webster e Tricard [9] o rebolo engloba quatro partes fundamentais, conforme a figura 2.

- Grãos: convencionais e superabrasivos;

- Ligantes: unem e suportam todos os abrasivos;

- Porosidade: acomodam os cavacos gerados e transportam os fluidos. Pode ser natural ou arti- 
ficial;

- Design: perfil de rebolo, camada de abrasivo, material do corpo, resistência à força rotacional, precisão e resistência ao ataque químico.

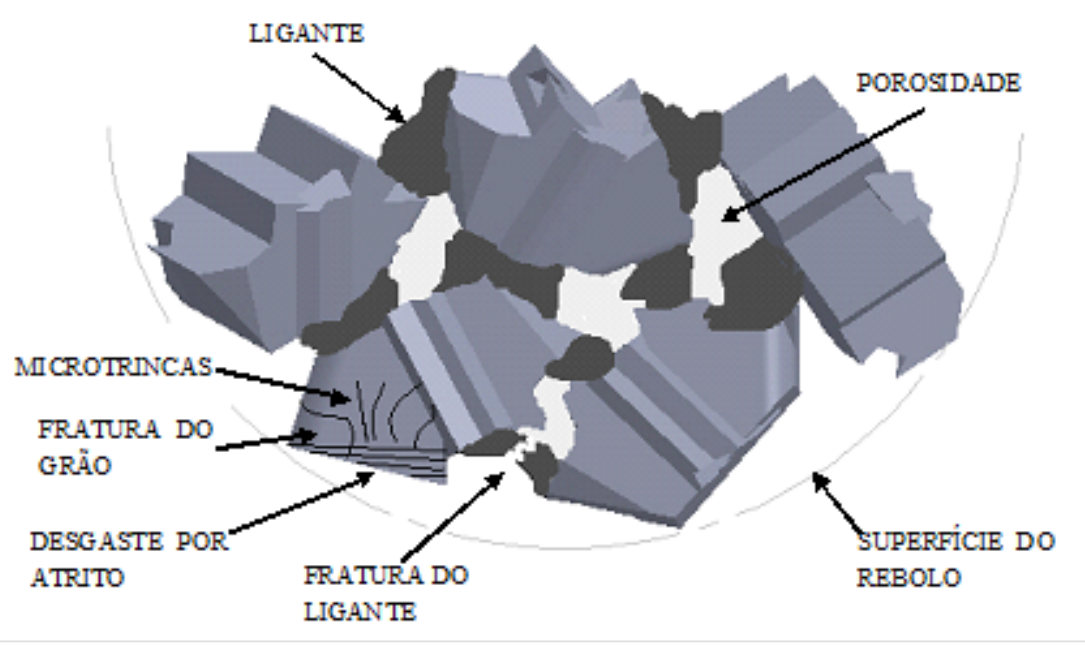

Figura 2: Principais constituintes do rebolo (adaptado de Machado et al., 2012).

Uma imprescindível propriedade de um abrasivo é que este seja mais duro do que o material a ser retificado. A dureza de um abrasivo é, casualmente, definida em termos de resistência e endentação estática obtida através de um teste de dureza Knoop [5]. Este método consiste em realizar uma micro endentação na amostra com uma ponta de diamante lapidado no formato piramidal sob a variação de diversas cargas. O valor da dureza é então definido pela medição da diagonal da marca produzida pelo diamante e relacionando-a com a carga utilizada [10].

Os grãos abrasivos usados nas operações de retificação são partículas refratárias duras e frágeis que podem ser classificadas de acordo com sua dureza ou composição química [11].

\section{FLUIDOS DE CORTE NO PROCESSO DE RETIFICAÇÃO}

Segundo Pawlak et al [12], os fluidos de corte foram aplicados na usinagem dos materiais com o propósito de reduzir, através da lubrificação, as características dos processos tribológicos que estão sempre presentes na superfície de contato entre a peça e a ferramenta e também reduzir o calor na região de corte através da refrigeração.

De acordo com Stanford e Lister [13], os fluidos de corte também promovem propriedades anticorrosivas à peça e à máquina ferramenta. Além dessas funções, os fluidos transportam os cavacos gerados e promovem a limpeza do rebolo [14].

Guo e Malkin [15] afirmam que, no processo de remoção do material, o calor irá gerar deformação térmica na máquina e na peça e, então, a precisão da usinagem fica limitada. Esse calor provém do atrito entre peça e rebolo. Se lubrificante é aplicado, o calor pode ser reduzido pela diminuição do atrito e, com isso, as forças serão menores e a tensão residual também. Segundo Ramesh [16], uma boa aplicação de refrigerante evita tensão residual, pois reduz a tensão térmica e mecânica durante a formação do cavaco.

Quando se aplica fluido de corte no processo de retificação, o tipo de refrigerante, sua composição, a posição do bocal e seu design e vazão são parâmetros que influenciam na produtividade, qualidade da peça e desgaste do rebolo [17].

\section{A TÉCNICA DE MÍNIMA QUANTIDADE DE LUBRIREFRIGERAÇÃO}

Segundo Attanasio et al [18], os fluidos de corte custam em torno de 7-17\% dos custos do processo e as ferramentas 2-4\%. O uso do MQL para redução dos custos está associado à redução dos fluidos usados. Dessa forma, no MQL são usados fluidos da ordem de vazão de $\mathrm{ml} / \mathrm{h}$ ou l/min.

Assim, Obikawa et al [19] definem o MQL como a mínima quantidade de lubrificante, onde uma pequena quantidade de óleo é misturada com ar comprimido e direcionada diretamente na região de corte, evitando as inundações de óleo observadas na refrigeração convencional. 
Attanasio et al [18] ainda descrevem uma aplicabilidade interessante do MQL, onde este pode ser usado para a redução dos gastos com a ferramenta na retificação de aços endurecidos com rebolo de CBN. Sendo assim, algumas vantagens são: cavaco, peça e ferramenta apresentam menor resíduo de fluido, sendo a limpeza dos mesmos mais fáceis e econômica. Além do mais, durante a usinagem, a peça não é totalmente coberta com fluido e é fácil de ser observada.

\section{O AÇO VP-50}

O aço VP50 é o material que foi usado. Sendo fornecido pela VILLARES METALS. Este aço é desenvolvido especialmente para fabricação de moldes para conformação de polímeros termoplásticos. Sua composição química é $0,15 \%$ de Carbono, 0,3\% de Silício, 1,55\% de manganês, 3\% de Níquel, 1\% de Alumínio, 1\% de Cobre em sua composição. Esse aço é endurecível por precipitação, possuindo resistência ao desgaste, elevado grau de pureza e também boa usinabilidade. Envelhecido, possui dureza de 40-42 HRc, já solubilizado possui uma dureza de 30-35 HRc, para envelhecimento após usinagem de acabamento. Por ser inoxidável, permite aplicação em processos corrosivos, como a conformação de polímeros clorados.

\section{ESPESSURA EQUIVALENTE DE CORTE}

Segundo Peters e Decneut [20] citado por Oliveira [21], a espessura da camada de material removida pelo rebolo numa volta completa denomina-se de espessura equivalente de corte $h_{\text {eq }}$, e é um parâmetro que permite quantificar uma condição de trabalho, sendo ainda definido como a relação entre a taxa de remoção específica do material Qw' e a velocidade de corte $\left(\mathrm{v}_{\mathrm{s}}\right)$.

De acordo com Graf [22] a espessura equivalente de corte pode ser representada pela equação (1):

$$
h_{e q}=\frac{Q_{w}^{\prime}}{v_{s}}=\frac{\pi \cdot d_{w} \cdot v_{f}}{60.1000 \cdot v_{s}}
$$

Onde,

$h_{e q}=$ espessura de corte equivalente $(\mu \mathrm{m})$;

$Q w^{\prime}=$ taxa específica de remoção de material $\left(\mathrm{mm}^{2} / \mathrm{s}\right)$;

$v_{s}=$ velocidade tangencial do rebolo $(\mathrm{m} / \mathrm{s})$;

$d_{w}=$ diâmetro da peça $(\mathrm{mm})$;

$v_{f}=$ velocidade de mergulho ou avanço $(\mathrm{m} / \mathrm{s})$;

$v_{s}=$ velocidade tangencial do rebolo $(\mathrm{m} / \mathrm{s})$.

Apesar da espessura equivalente de corte não levar em consideração o espaçamento dos grãos do rebolo, pode ser considerado um dos melhores parâmetros de caracterização de um processo de retificação uma vez que engloba três importantes características do processo $\left(\mathrm{v}_{\mathrm{s}}, \mathrm{v}_{\mathrm{f}}, \mathrm{d}_{\mathrm{w}}\right)$ [23].

Segundo Malkin [5], a espessura equivalente de corte está diretamente relacionada ao comportamento do processo de retificação em função das variáveis envolvidas tais como, além da força de corte, rugosidade, topografia da ferramenta, entre outras.

\section{POTÊNCIA NA RETIFICAÇÃO}

Segundo Malkin [24], a potência $(\mathrm{P})$ de retificação é associada à velocidade de corte $\left(\mathrm{V}_{\mathrm{s}}\right)$ e velocidade da peça $\left(\mathrm{V}_{\mathrm{w}}\right)$, segundo a equação (2). Marinescu et al [23] ainda relatam que a força tangencial é a componente da força de retificação responsável pela dissipação de potência em situações de alta velocidade do rebolo.

$$
P=F_{t} \cdot\left(v_{s} \pm v_{w}\right)
$$

$\mathrm{O}$ sinal positivo indica que $\mathrm{v}_{\mathrm{s}}$ e $\mathrm{v}_{\mathrm{w}}$ têm direções opostas e o sinal negativo indica mesma direção. Entretanto, se $\mathrm{v}_{\mathrm{s}}$ é muito maior que $\mathrm{v}_{\mathrm{w}}$, a equação da potência fica como na equação (3).

$$
P=F_{t} \cdot v_{s}
$$

Geralmente, a potência associada ao avanço e à velocidade transversal é desprezada. 


\section{EMISSÃO ACÚSTICA}

Nos últimos anos, o uso do monitoramento dos processos de usinagem tem sido feito para providenciar maior qualidade do produto [25]. A emissão acústica tornou-se uma boa opção, pois todos os materiais emitem sons a alta frequência quando submetidos a um esforço ou quando são deformados ou fraturados. A vantagem dessa técnica é que o processo pode ser monitorado instantaneamente. No entanto, esta variável é limitada pelos ruídos externos.

A emissão acústica é definida como onda elástica transiente gerada por uma rápida liberação de energia de uma fonte localizada no material quando submetido a um estado de tensão. A energia liberada está associada a uma abrupta redistribuição de tensão e com isso uma onda é propagada pelo material [26]. Na maioria das vezes, a emissão acústica está ligada à interação entre o grão do rebolo e a superfície do material.

\section{RUGOSIDADE}

A rugosidade é uma propriedade que define, em partes, a qualidade superficial de uma peça usinada e, segundo Svirshchev et al [27], os parâmetros do processo e também da ferramenta abrasiva influenciam nessa variável.

Nesse aspecto, Malkin [24] define que a qualidade superficial é dividida em dois aspectos:

- Integridade superficial; influenciada pelas solicitações mecânicas e térmicas que a peça é sub-metida.

- Textura da superfície; caracterizada pela topografia da peça e está associada à rugosidade.

\section{CIRCULARIDADE}

O erro de circularidade é definido como qualquer diferença entre a peça usinada e a projetada com tolerâncias especificadas [28]. O desvio de circularidade é identificado por dois limites circulares concêntricos que compreendem o maior pico e menor vale de um perfil.

O erro de circularidade ocasionado pelo processo durante a usinagem está diretamente relacionado com as condições de retificação, os danos térmicos, as solicitações mecânicas, a pressão e a vazão de fluido de corte utilizado.

\section{ANÁLISE DA MICROESTRUTURA - MICROSCOPIA ELETRÔNICA POR VARREDURA}

O processo de retificação requer uma extrema energia inicial por unidade de volume de material removido. Toda essa energia é convertida em calor que é concentrado na zona de corte. A elevada temperatura obtida pode causar vários danos térmicos, como queima da superfície da peça, transformação de fase, amolecimento superficial e até mesmo aumento da tensão residual, trincas e diminuição da resistência à fadiga [24].

Com isso, a queima superficial pode ocasionar uma retempera, originando uma microestrutura frágil que prejudicará a resistência à fadiga. Entretanto, em função do aquecimento do material durante a retificação e também da taxa de resfriamento proporcionada pelo refrigerante, pode ocorrer o revenimento e perda de dureza superficial.

Segundo Marinescu et al [29], a microscopia eletrônica de varredura (MEV) é muito utilizada na caracterização de superfícies fraturadas, para investigar a estrutura superficial, detectar falhas e poros abertos. Um feixe de elétrons de 0,01 $\mu \mathrm{m}$ de diâmetro varre a superfície linearmente e o impacto dos elétrons primários provoca a emissão de elétrons secundários da amostra.

\section{MATERIAIS E MÉTODOS}

Os experimentos foram executados na retificadora cilíndrica CNC fabricada pela empresa Sulmecânica, modelo RUAP $515 \mathrm{H}$.

Os rebolos utilizados nos ensaios foram; os rebolos convencionais de carbureto de silício verde ( $\mathrm{SiC}$ ), carbureto de silício preto com óxido de alumínio branco $\left(\mathrm{SiC}+\mathrm{Al}_{2} \mathrm{O}_{3}\right)$ e óxido de alumínio branco $\left(\mathrm{Al}_{2} \mathrm{O}_{3}\right)$, todos com dimensões de: diâmetro externo $350 \mathrm{~mm}$, diâmetro interno de $127 \mathrm{~mm}$ e espessura de $30 \mathrm{~mm}$, granulometria de 60 mesh, ligante vitrificado e densidade da estrutura nível 7 fornecidos pela empresa ABRASIPA.

O sistema de refrigeração convencional utilizado é o mesmo utilizado em várias empresas atualmente. Consiste essencialmente na caixa reservatória de fluido, moto bomba de sucção, mangueiras, bocais aplicado- 
res e o fluido de corte. A caixa reservatória tem capacidade de 80 litros. Foi preparado uma emulsão com $5 \%$ em água do óleo semissintético ROCOL 4847 Ultracut 370 e aplicado no processo com uma vazão de 16 $\mathrm{L} / \mathrm{min}$.

A aplicação do MQL foi feita basicamente utilizando um compressor, regulador de pressão, medidor de vazão de ar, dosador (equipamento de MQL) e bocal projetado para sua utilização na retificação. O equipamento de mínima quantidade de lubrificante permite uma fina regulagem do volume de lubrificante/ar separadamente, por meio de um registro tipo agulha, atomizando-o em um fluxo de ar à pressão constante de 637,4 kPa, aproximadamente. O fluido de corte utilizado na MQL foi o óleo AccuLube LB 1000, fornecido pela empresa ITW Chemical Products Ltda., a uma vazão de $120 \mathrm{ml} / \mathrm{h}$.

Os corpos de prova que foram utilizados para os ensaios são feitos de aço VP50, o qual possui tratamento térmico de envelhecimento com dureza de 40-42 HRc, fabricado e doado pela empresa VILLARES METALS por intermédio do Laboratório de Ensino e Pesquisa em Usinagem, da Universidade Federal de Uberlândia, sendo que esse aço é utilizado na fabricação de moldes para injeção de polímeros termoplásticos. As características do aço são: resistência ao desgaste e elevado grau de pureza, tendo 0,15\% de Carbono, 0,3\% de Silício, 1,55\% de Manganês, 3\% de Níquel, 1\% de Alumínio, 1\% de Cobre em sua composição.

As dimensões do corpo de prova são: diâmetro externo 75,0 $\pm 0,1 \mathrm{~mm}$, diâmetro interno 30,0 $\pm 0,1 \mathrm{~mm}$, espessura 4,0 $\pm 0,1 \mathrm{~m}$.

A espessura de corte equivalente é um importante parâmetro determinado pela variação da profundidade de corte com a velocidade da peça e a velocidade periférica do rebolo em regime constante.

A força tangencial de corte foi medida pela determinação da potência elétrica consumida pelo motor de acionamento do eixo árvore do rebolo, com o monitoramento dos valores de tensão e corrente elétrica, provenientes deste motor elétrico.

O desgaste diametral do rebolo foi medido por meio do método de impressão do perfil do rebolo desgastado em um corpo devidamente preparado para tal fim. O método consiste na retificação do corpo, retirando um volume fixo de material. Feito isso, os desníveis existentes entre as regiões gastas e não gastas do rebolo foram repassados ao corpo retificado, que será então medido pelo rugosímetro Surtronic3+, utilizado juntamente com o software TalyMap, ambos da Taylor Hobson.

A medição da emissão acústica foi feita com a utilização de um módulo DM12, da marca Sensis, com um sensor fixo que foi posicionado no cabeçote móvel da retificadora próximo do contraponto, com o intuito de detectar as possíveis variações deste sinal e sua relação com as outras variáveis de saída.

A aquisição dos dados foi realizada através de um computador com placa de aquisição de dados A/D e software LabVIEW versão 7.1 do fabricante National Instruments. Os parâmetros que foram coletados são: potência elétrica (Pelet) consumida pelo motor de acionamento do rebolo, rotação da ferramenta (n) e emissão acústica (EA). A força tangencial de corte foi medida pela determinação da potência elétrica consumida pelo motor de acionamento do eixo árvore do rebolo, com o monitoramento dos valores de tensão e corrente elétrica, provenientes deste motor elétrico. As aquisições dos dados foram realizadas em tempo real e armazenadas através do software na forma de tensão $(\mathrm{V})$ para posterior manipulação dos dados através do software MatLab, da empresa MathWorks. O sistema de aquisição foi programado para operar com uma taxa de aquisição de 1000 pontos por segundo.

A medição da rugosidade superficial foi obtida através de um rugosímetro Surtronic3+, da marca Taylor Hobson, que fará a medição da rugosidade média (Ra) dos corpos de prova usinados e foram comparadas segundo a velocidade de mergulho e o método de lubrirrefrigeração utilizado. Cada peça foi medida três vezes com uma variação aproximada na superfície com um ângulo de aproximadamente $120^{\circ}$ entre cada medição. Para os valores apresentados foi considerada a média das três medições efetuadas.

A circularidade foi obtida através da utilização de um medidor de circularidade, modelo Talyrond 31C, marca Taylor Hobson.

As análises de microestrutura foram realizadas no laboratório de materiais da própria Faculdade de Engenharia de Bauru, necessitando apenas de uma devida preparação dos corpos de prova. As fotos micrografias de MEV foram obtidas em um equipamento ZEISS LEO 440 (Cambridge, England) com detector OXFORD (model 7060), operando com feixe de elétrons de 20kV.

Foram realizados dezoito ensaios sendo seis para cada tipo de rebolo e três para cada tipo de lubrirrefrigeração, onde variou-se as velocidades de mergulho. Para os experimentos foram estabelecidas as seguintes condições de usinagem: velocidade de corte $\left(\mathrm{v}_{\mathrm{s}}\right)$ de $30 \mathrm{~m} / \mathrm{s}$, diâmetro da peça $\left(\mathrm{d}_{\mathrm{w}}\right)$ de $75 \mathrm{~mm}$ e as três velocidades de mergulho escolhidas foram $0,25 \mathrm{~mm} / \mathrm{min}, 0,50 \mathrm{~mm} / \mathrm{min}$ e $0,75 \mathrm{~mm} / \mathrm{min}$. Desse modo, de acordo com a equação (1), as três espessuras equivalentes de corte ora denominadas por $h_{\mathrm{eq}}(1), \mathrm{h}_{\mathrm{eq}}(2)$ e $\mathrm{h}_{\mathrm{eq}}(3)$ 
foram: $h_{\mathrm{eq}}(1)=0,0327 \mu \mathrm{m}, \mathrm{h}_{\mathrm{eq}}(2)=0,0654 \mu \mathrm{m}$ e $\mathrm{h}_{\mathrm{eq}}(3)=0,0981 \mu \mathrm{m}$.

\section{RESULTADOS}

A seguir são apresentados os resultados obtidos para cada experimento de retificação realizado. As variáveis de saída: potência de usinagem, desgaste diametral e emissão acústica, e para os resultados de análise da integridade estrutural foram avaliados a rugosidade, a circularidade e a microestrutura.

\subsection{Potência de corte}

Neste item são apresentados os resultados da potência de retificação (W) em função dos tipos de rebolos, da espessura equivalente de corte e das condições de lubrirrefrigeração utilizadas. Através da manipulação e conversão dos dados obtidos em tempo real durante os ensaios, construíram-se gráficos para as potências de corte conforme pode-se observar na figura 3.

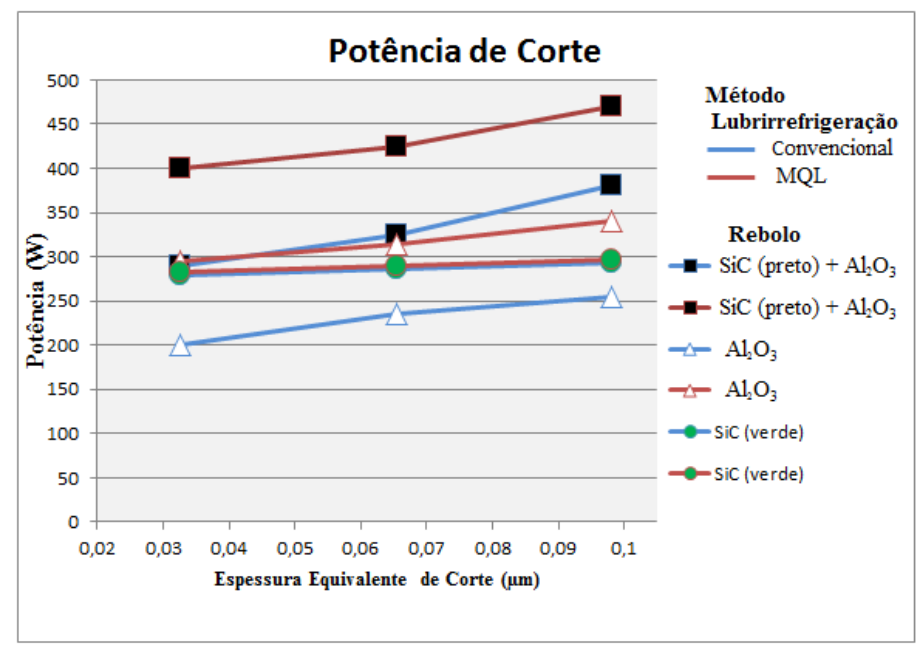

Figura 3: Resultado da potência de corte

No ensaio utilizando o rebolo de carbureto de silício preto com óxido de alumínio branco, e o método de lubrirrefrigeração MQL notou-se que houve uma maior componente tangencial contrária à rotação do rebolo, aumentando, assim a potência de usinagem.

Já nos ensaios onde foram utilizados o rebolo de óxido de alumínio branco e o rebolo de carbureto de silício verde, nas condições dos ensaios realizados, não houve alterações dos valores de velocidades relacionadas diretamente com a potência, sendo que a única variável que foi alterada durante os ensaios foi a força tangencial de corte. Assim, é de se esperar que com o aumento da espessura equivalente de corte, ocorra o aumento da força de corte tangencial devido ao atrito, proporcionando um aumento na potência, este comportamento é observado em ambos os tipos de lubrirrefrigeração. Entretanto, se o rebolo sofre um maior desgaste, a taxa de formação de arestas de corte é muito grande, sempre deixando uma área de contato de grão com a peça pequena, diminuindo a força de corte envolvida no processo [30], o que naturalmente causa uma menor potência envolvida.

\subsection{Desgaste diametral do rebolo}

Em relação ao desgaste diametral dos rebolos, a figura 4 mostra os dados obtidos em função da espessura equivalente de corte e do método de lubrirrefrigeração utilizado. 


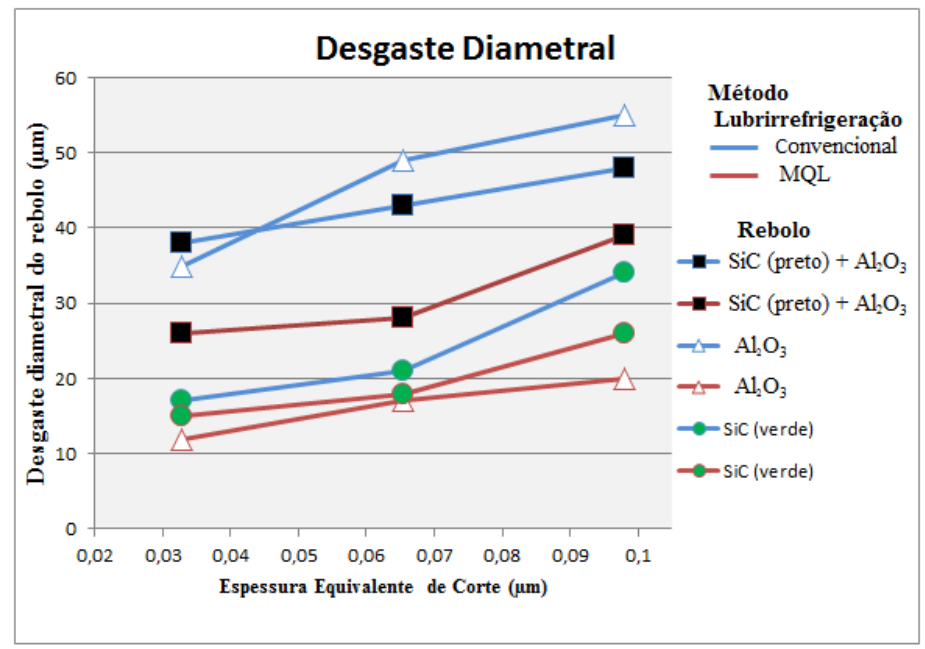

Figura 4: Comparação das medidas de desgaste diametral

É possível observar que com a utilização da lubrirrefrigeração por MQL o desgaste diametral do rebolo diminui consideravelmente.

Os valores de desgaste com a utilização do MQL são menores devido ao melhor efeito lubrificante deste, que reduz o atrito na região de contato entre peça e rebolo, diferentemente do método convencional, que por sua vez possui melhor efeito refrigerante do que lubrificante, não sendo tão efetivo na redução de atrito e atuando melhor na remoção de calor.

Pode-se verificar que quando são utilizados ambos os processos de lubrirrefrigeração, a tendência do comportamento do desgaste diametral do rebolo é o mesmo; ou seja, há o aumento desta variável conforme a espessura de corte equivalente aumenta.

Nos processos de retificação onde foram utilizados os rebolos de carbureto de silício preto com óxido de alumínio branco e o rebolo de carbureto de silício verde, a técnica MQL foi mais eficiente na redução do desgaste em comparação com a técnica convencional, além do padrão esperado de aumento de desgaste com o aumento do avanço, que naturalmente gera um maior atrito na região de contato ferramenta-peça, acarretando num aumento do desgaste sofrido pelo rebolo.

\subsection{Emissão acústica}

Na figura 5, são mostrados os resultados da emissão acústica (RMS) em Volts (V) em função do tipo de rebolo, da espessura de corte equivalente e das condições de lubrirrefrigeração.

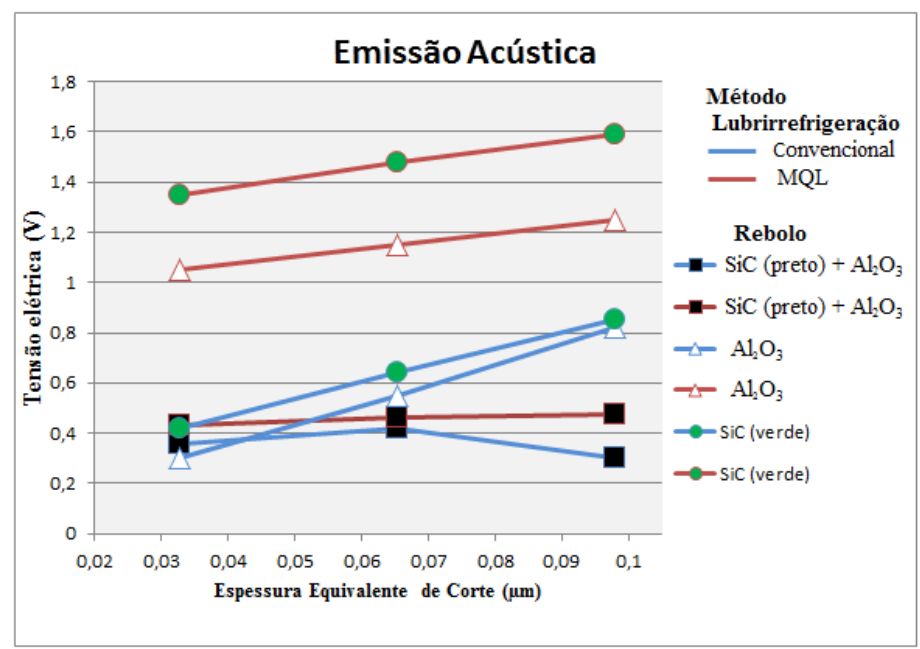

Figura 5: Resultado da emissão acústica

De acordo com Babel [31], a emissão acústica engloba características referentes a fenômenos como a 
formação de cavacos, atrito, fratura de ligante e a transição de fase termomecânica ativa. A emissão acústica pode ser definida como ondas de tensão elásticas, geradas pela liberação de energia de deformação dentro do material [32].

De uma forma geral, na utilização dos três tipos de rebolos é notada a maior liberação de energia na lubrificação com MQL, devido a fatores tais como a formação de cavaco e a menor dissipação de temperatura pela pouca refrigeração do óleo. Embora a utilização do MQL tenha uma característica de aplicação mais eficiente, não foi capaz de remover de forma satisfatória os cavacos encrustados no rebolo, influenciando na emissão acústica. Entretanto, é perceptível o decréscimo da emissão acústica com o aumento da vf para o MQL e o seu respectivo aumento para a refrigeração convencional, fator esse que ocorre devido à influência do atrito que é reduzido de acordo com o padrão exibido pelo gráfico de potência envolvida no processo.

Tanto nos ensaios onde foi utilizado o método convencional de lubrirrefrigeração, como nos ensaios onde foi utilizado o MQL, há um aumento dos valores de emissão acústica conforme a velocidade de mergulho aumentou.

\subsection{Rugosidade}

Na figura 6, são apresentadas as medições da rugosidade de acordo com cada tipo de rebolo apresentadas em rugosidade média $\mathrm{R}_{\mathrm{a}}$ de cada peça, comparando-se segundo a sua velocidade de mergulho e tipo de lubrirrefrigeração. A superfície de cada peça foi medida três vezes, com uma distância de $120^{\circ}$ entre as posições medidas.

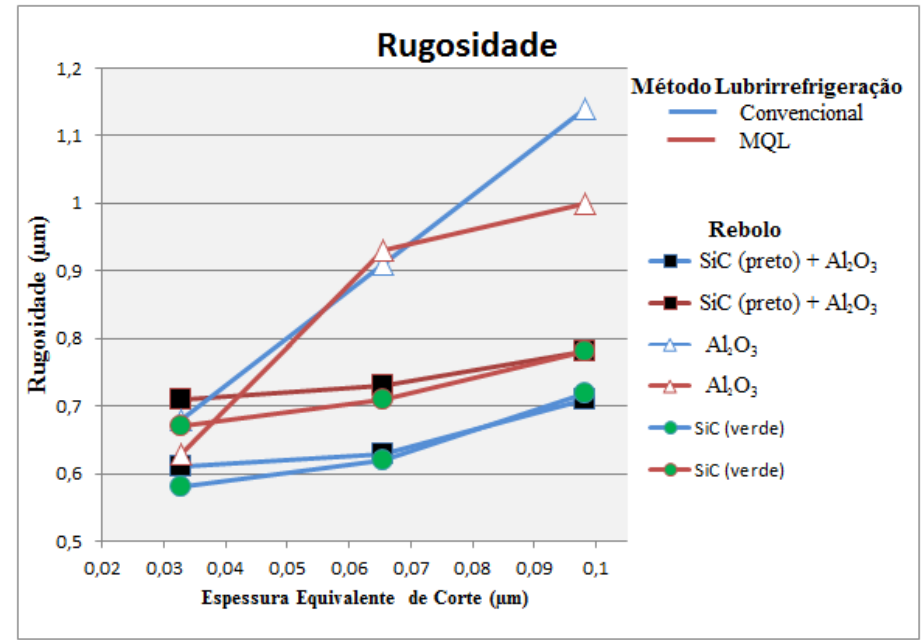

Figura 6: Comparação das medidas de rugosidade

Analisando a figura 6 pode-se observar inicialmente que os valores de rugosidade para os três tipos de rebolo, estão abaixo do valor caracterizado como aceitável para o processo de retificação que é de 1,6 $\mu$ m [5]. Conforme há o aumento da velocidade de mergulho, os valores médios da rugosidade aumentam a taxa de remoção de material. Na condição de lubrirrefrigeração convencional onde se tem um maior fluxo de fluído que elimina os cavacos da área de corte com maior eficiência na refrigeração, está condição é importante para exatidão geométrica, dimensional e para a baixa rugosidade na peça, como se pode observar.

É possível identificar que utilizando o método de lubrirrefrigeração MQL, para os três rebolos o resultado da rugosidade foi maior, com exceção do rebolo de óxido de alumínio branco utilizando o método de lubrirrefrigeração convencional que apresentou maior grau de rugosidade. Possivelmente o fato do rebolo de óxido de alumínio branco ter uma friabilidade maior que os demais rebolos pode ter contribuído para uma maior rugosidade na peça.

Na retificação com MQL, embora a quantidade de fluido utilizado seja substancialmente menor do que na retificação com refrigeração convencional, a forma de aplicação é mais eficiente. A explanação para isto está no fato de que no MQL, a velocidade de mistura ar-óleo entra na região de corte com a mesma velocidade periférica do rebolo, assim acontece a quebra da barreira aerodinâmica do ar em torno do rebolo, facilitando assim a sua penetração. 
A porosidade natural do ligante vitrificado também contribui para o alojamento dos cavacos, facilitando o fluxo do MQL. Assim, o fluido de MQL sendo aplicada na mesma velocidade periférica do rebolo, a penetração do mesmo na zona de contato rebolo/peça é tão eficiente quanto à utilização do fluido convencional a baixas velocidades de aplicação com alta vazão.

Segundo Attanasio et al [18], a condição convencional tem um maior fluxo de fluido e elimina os cavacos da zona de corte mais eficientemente. A eficiência da refrigeração é importante para a exatidão geométrica, dimensional e para a baixa rugosidade na peça. Sendo assim este método apresenta uma efetividade muito boa quando se trata de rugosidade.

É possível notar que com o aumento da espessura equivalente de corte a situação de corte torna-se mais severa elevando um pouco os valores de rugosidade, principalmente quando utilizado o rebolo de óxido de alumínio branco.

\subsection{Circularidade}

A figura 7 apresenta os valores dos desvios de circularidade expressos em micrometros ( $\mu$ m) em função do tipo de rebolo, espessura equivalente de corte e o método de lubrirrefrigeração.

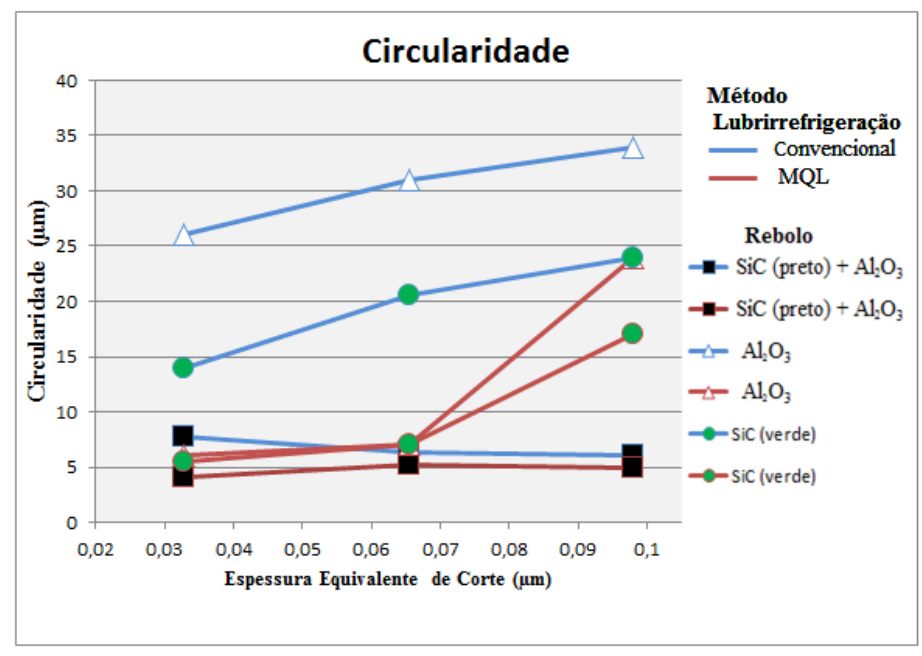

Figura 7: Comparação das medidas de circularidade

No processo de retificação o desgaste do rebolo está diretamente ligada ao tipo de lubrificação utilizada, no caso do rebolo convencional de carbureto de silício preto com óxido de alumínio branco o método de lubrificação MQL apresentou os melhores valores de circularidade. Segundo Minke [33], os elevados atritos gerados durante o processo de retificação (principalmente entre a peça e o rebolo), podem ser considerados um fator de extrema importância para o aparecimento dos erros de circularidade, sendo que para a redução destes atritos, um fluido com boa capacidade lubrificante, além da refrigerante é recomendável, a fim de se melhorar a qualidade final da peça retificada.

Já com a utilização dos rebolos de óxido de alumínio branco e carbureto de silício verde, analisando de forma geral os gráficos, observa-se uma tendência de aumento de desvio de circularidade em proporção do aumento da velocidade de mergulho. Com a utilização desses dois rebolos é possível notar que com a utilização do MQL, os erros de circularidade também aumentam conforme o aumento da velocidade de mergulho, porém sempre com valores abaixo dos aquisitados nos ensaios utilizando lubrirrefrigeração convencional. É possível observar também que na condição de lubrirrefrigeração convencional onde os erros de circularidade foram maiores, o rebolo de carbureto de silício preto com óxido de alumínio branco obteve um baixo erro de circularidade, provavelmente pelo carbureto de silício preto apresentar uma alta resistência ao desgaste.

\subsection{Análise metalográfica}

Para detectar possíveis variações microestruturas nas peças retificadas utilizando-se os três tipos de rebolos, foi feita análise metalográfica. Os corpos de prova foram submetidos aos devidos ataques químicos para avaliações microscópicas. A aproximação usada foi de 500x, que é suficiente para detectar qualquer variação significativa em sua estrutura. 
As figuras 8, 9 e 10 representam metalografias do corpo de prova após o processo de retificação com o rebolo convencional de carbureto de silício preto com óxido de alumínio branco.

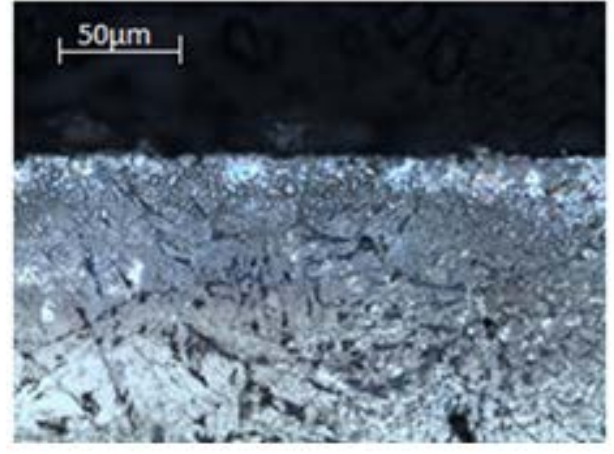

(a)

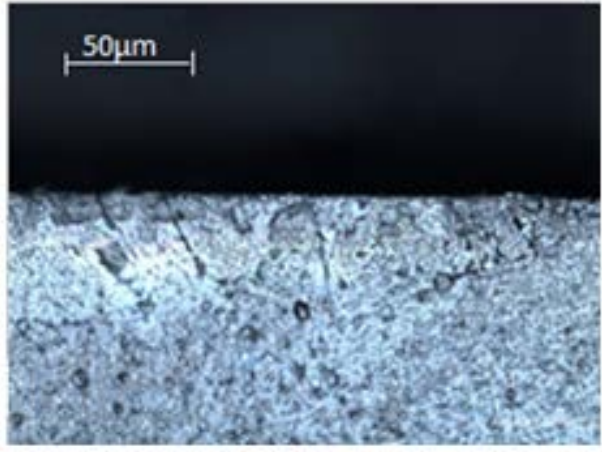

(b)

Figura 8: Metalografia dos ensaios com $\mathrm{h}_{\mathrm{eq}}$ (1), ampliada. (a) Convencional, (b) MQL

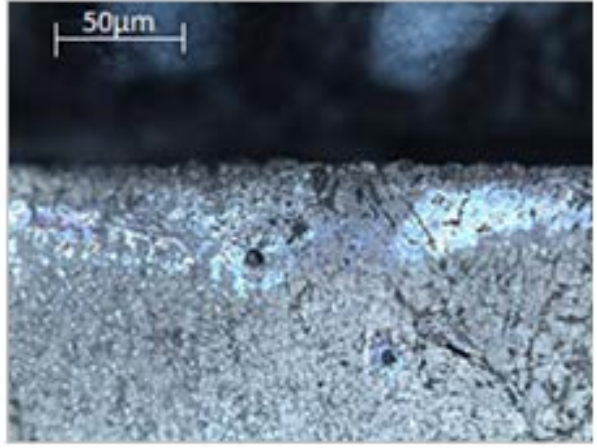

(a)

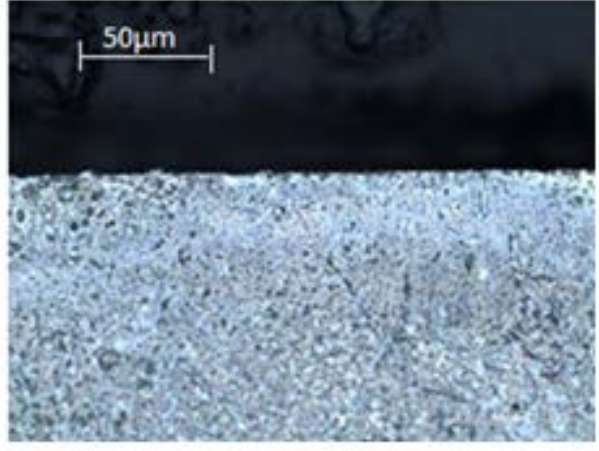

(b)

Figura 9: Metalografia dos ensaios com $\mathrm{h}_{\mathrm{eq}}$ (2), ampliada. (a) Convencional, (b) MQL

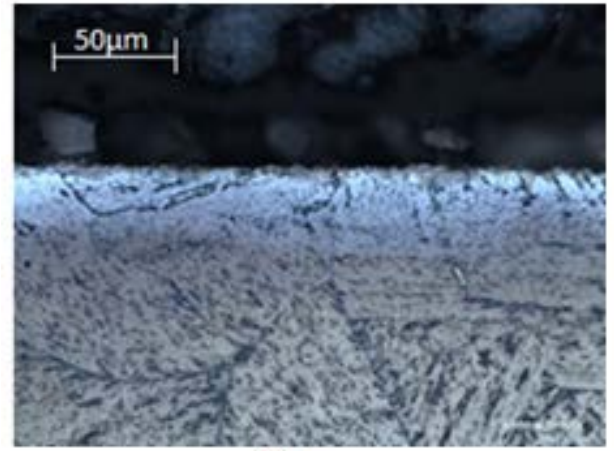

(a)

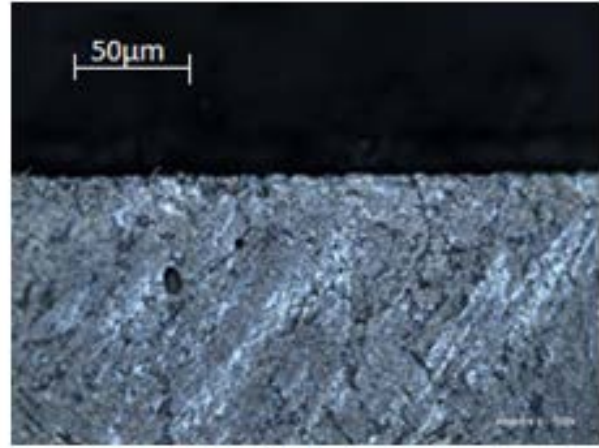

(b)

Figura 10: Metalografia dos ensaios com $h_{\text {eq }}$ (3), ampliada. (a) Convencional, (b) MQL

Fazendo uma análise geral, não foi encontrada nenhuma evidência que demostre que houve algum dano térmico nas amostras, isso mostra que o conjunto rebolo mais os dois tipos de refrigeração usados, foram eficientes para evitar qualquer tipo de queima.

As figuras 11, 12 e 13 representam metalografias do corpo de prova após o processo de retificação com o rebolo de óxido de alumínio branco. 


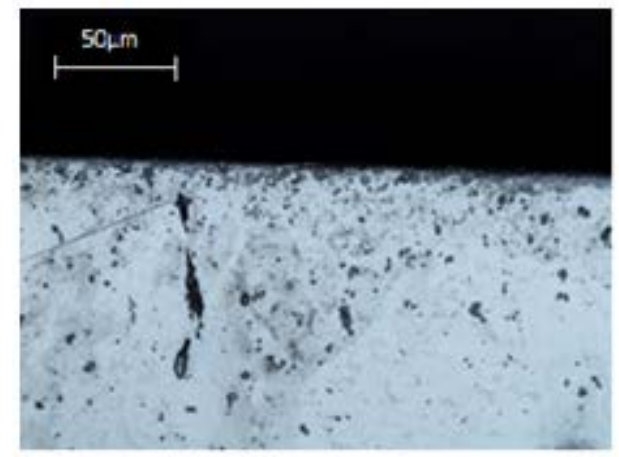

(a)

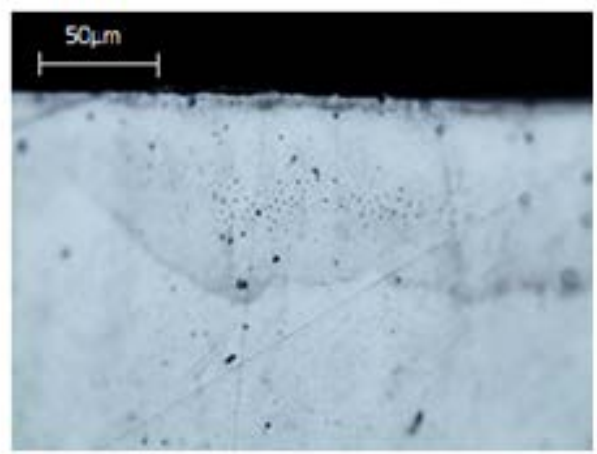

(b)

Figura 11: Metalografia dos ensaios com $\mathrm{h}_{\mathrm{eq}}$ (1), ampliada. (a) Convencional, (b) MQL

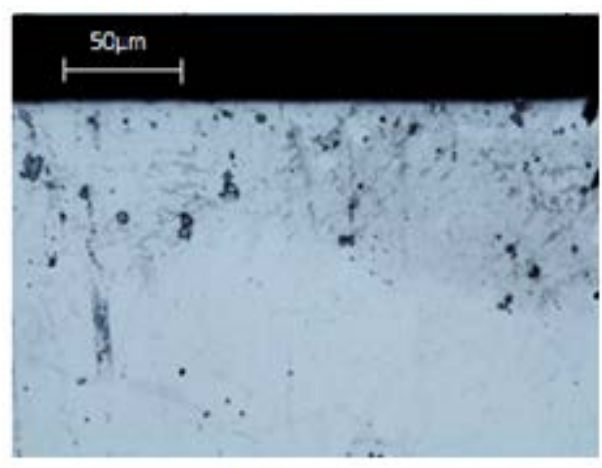

(a)

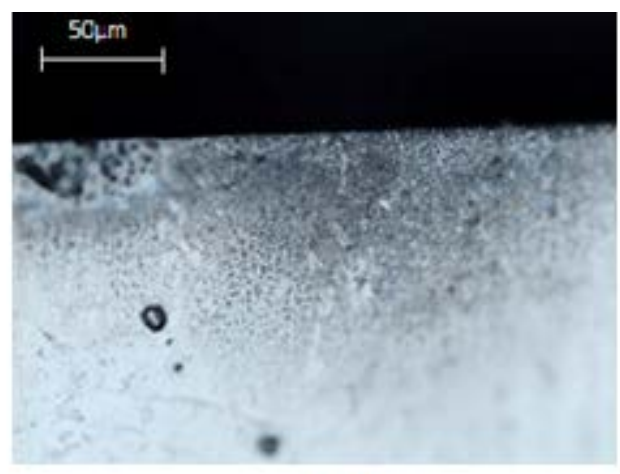

(b)

Figura 12: Metalografia dos ensaios com $\mathrm{h}_{\mathrm{eq}}$ (2), ampliada. (a) Convencional, (b) MQL

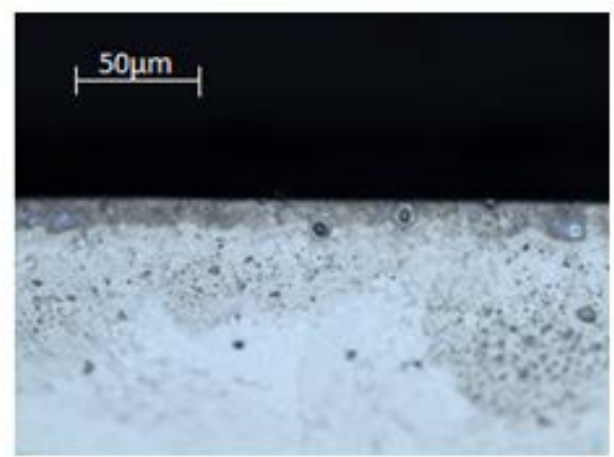

(a)

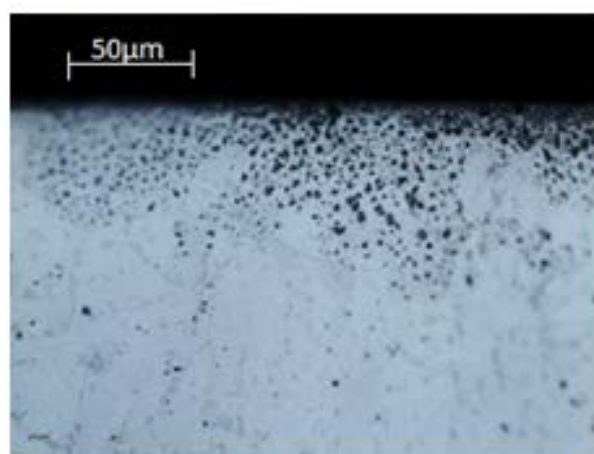

(b)

Figura 13: Metalografia dos ensaios com $\mathrm{h}_{\mathrm{eq}}$ (3), ampliada. (a) Convencional, (b) MQL

Após análise da metalografia do processo de retificação nos corpos de prova utilizado nos três tipos de rebolo, é possível afirmar que não houve dano térmico, apesar do rebolo de óxido de alumínio possuir uma baixa condutividade térmica, a refrigeração em ambos os métodos foram suficientes para evitar qualquer tipo de queima.

As figuras 14 e 15 representam metalografias do corpo de prova após o processo de retificação com o rebolo de carbureto de silício verde. 


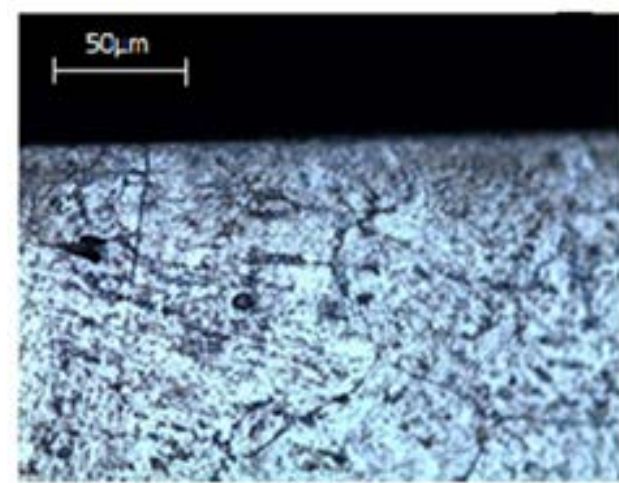

(a)

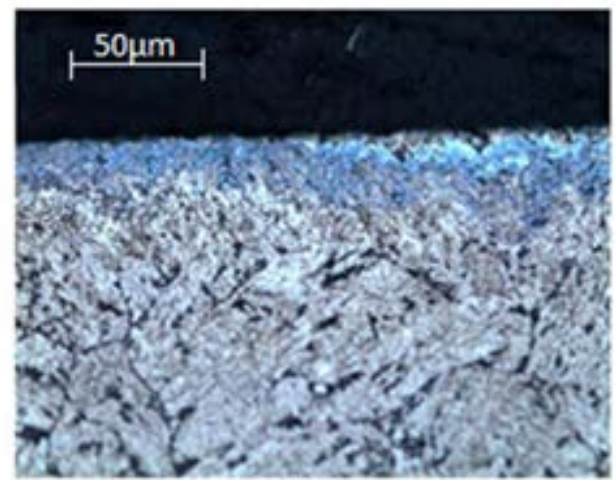

(b)

Figura 14: Metalografia dos ensaios com $\mathrm{h}_{\mathrm{eq}}$ (1), ampliada. (a) Convencional, (b) MQL

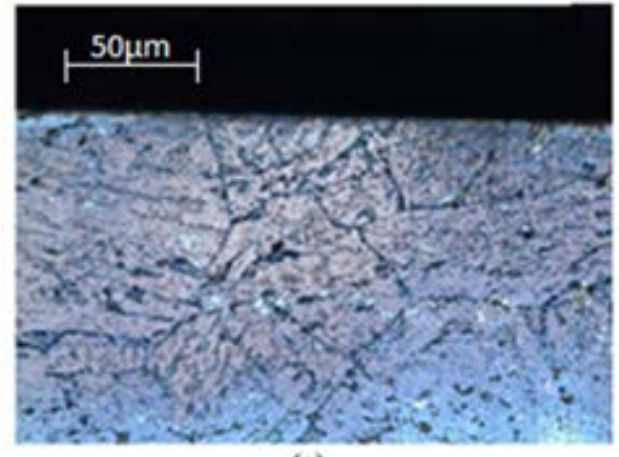

(a)

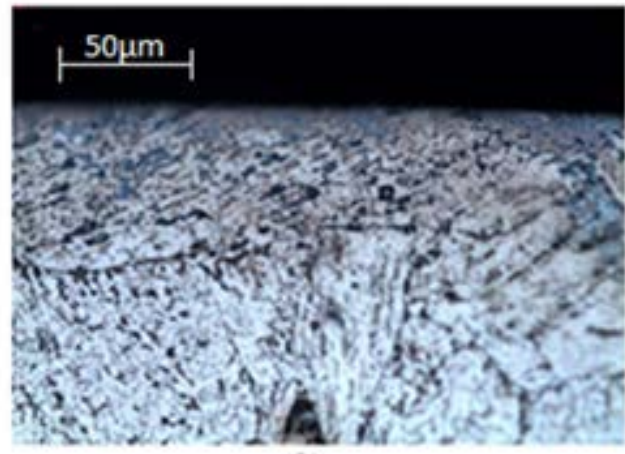

(b)

Figura 15: Metalografia dos ensaios com $h_{\text {eq }}$ (3), ampliada. (a) Convencional, (b) MQL

Pode-se verificar nas figuras dos corpos de prova que foram retificados com o rebolo de carbureto de silício verde que não ocorreu variação significativa provocada pela operação de retificação. Assim, pode-se afirmar que o processo de retificação não provocou alteração na estrutura da superfície do material.

\section{CONCLUSÕES}

Analisando os dados obtidos nos ensaios realizados com os corpos de prova do aço VP50, aplicação da lubrificação convencional e a técnica de mínima quantidade de lubrificação (MQL), quanto à utilização dos rebolos de carbureto de silício verde, óxido de alumínio branco e carbureto de silício preto com óxido de alumínio branco, pode-se observar que:

A qualidade superficial obtida atingiu os níveis aceitáveis de rugosidade característicos do processo, destacando os valores obtidos com a utilização dos rebolos de carbureto de silício preto com óxido de alumínio branco e carbureto de silício verde.

Quanto à circularidade dos rebolos após o processo de retificação, o rebolo de carbureto de silício preto com óxido de alumínio branco obteve os menores valores de variação da circularidade.

O rebolo de carbureto de silício verde apresentou uma melhor resistência ao desgaste em relação aos outros rebolos analisados. Nos três tipos de rebolo é possível verificar que a potência e o desgaste diametral seguem perfis indiretamente proporcionais de comportamento, para ambos os métodos de lubrirrefrigeração e todas as velocidades de mergulho.

Após a retificação dos corpos de prova com os três tipos de rebolos verificou-se em todos que não houve dano na superfície retificada, embora tenhamos verificado que houve um leve aumento da dureza do material em sua superfície. Complementarmente, não foi detectada a queima do material. Com base nos dados coletados e fazendo uma analise comparativa, pode-se apontar que para o processo de retificação do aço VP-50, o rebolo de carbureto de silício verde com a utilização de lubrirrefrigeração convencional apresentou uma melhor performance geral dentro dos parâmetros analisados. 


\section{BIBLIOGRAFIA}

[1] NGUYEN, T.A., BUTLER, D.L. "Simulation of precision grinding process, part 1: generation of the grinding wheel surface”, International Journal of Machine Tools \& Manufacture, v. 45, pp. 1321-1328, 2005.

[2] MARINESCU, I. D., HITCHINER, M., UHLMANN, E., et al., Handbook of machining with grinding wheels, Boca Raton, FL, CRC Press, Taylor \& Francis Group, 2007.

[3] TAWAKOLI, T., HADAD, M.J., SADEGHI, M.H., et al. “An experimental investigation of the effects of workpiece and grinding parameters on minimum quantity lubrication-MQL grinding”, International. Journal of Machine Tools \& Manufacture, v. 49, pp. 924-932, 2009.

[4] SALMON, S. C. Modern Grinding Process Technology, MacGraw-Hill, 1992.

[5] MALKIN, S. Grinding Technology: theory and applications of machining with abrasives, 2 ed., Industrial Press, 2008.

[6] REN, Y.H., ZHANG, B., ZHOU, Z.X. "Specific energy in grinding of tungsten carbides of various grain sizes”, CIRP Annals - Manufacturing Technology, v. 58, pp. 299-302, 2009.

[7] ANDERSON, D., WARKENTIN, A., BAUER, R. "Experimental validation of numerical thermal models for dry grinding”, Journal of materials processing technology, v. 204, p. 269-278, 2008.

[8] CAI, R., ROWE, W.B. “Assessment of vitrified CBN wheels for precision grinding”, International Journal of Machine Tools \& Manufacture, v. 44, p. 1391-1402, 2004.

[9] WEBSTER, J., TRICARD, M., "Innovations in Abrasive Products for Precision Grinding\|”, CIRP Annals - Manufacturing Technology, v. 53, 2004.

[10] BROOKES, C. A. "Diamond in perspective: a review of mechanical properties of natural diamond”, Dia-mond and related materials, v. I, pp 13-17, 2010.

[11] LIAO, T. W., TING, C. F., QU, J., et al. “A wavelet-based methodology for grinding wheel condition monitoring”, International Journal of Machine Tools \& Manufacture. v. 47, pp. 580-592, 2007.

[12] PAWLAK, Z., KLAMECKI, E. B., RAUCKYTE, T., et al, The Tri-bochemical and Micellar Aspects of Cutting Fluids, Tribology International, v. 38, 2004.

[13] STANFORD, M., LISTER, P.M. "Future role of metalworking fluids”, Industrial Lubrification Tribology, v. 54, n.1, p. 11-19, 2007.

[14] TAWAKOLI, T., WESTKAEMPER E., RABIEY M. Dry grinding by special conditioning. International Journal of Advanced Manufacturing Technology, v. 33, pp. 419-424, 2007.

[15] GUO, C., MALKIN, S. Energy Partition and Cooling During Grinding. Journal of Manufacturing Processes, v 2/No. 3, 2000.

[16] RAMESH K., YEO S. H., GOWRI S., ZHOUL L., "Experimental Evaluation of Super High SpeedGrinding of Advanced Ceramics”, International Journal of Advanced Manufacturing Technology, v.17, pp.87-92, 2001.

[17] BRINKSMEIER, E.; HEINZEL, C.; WITTMAN, M. "Friction, cooling and lubrication in grinding”. CIRP Annals. v. 48, No.2, p. 581-598, 1999.

[18] ATTANASIO, A., GELFI, M., GIARDINI, C., REMINO, C., "Minimal quantity lubrication in turning: Effect on tool wear”, Wear, v. 260, n.3 , pp. 333-338, February, 2006.

[19] OBIKAWA, T., KAMATA, Y., SHINOZUKA, J., “High-speed grooving with applying MQL”, International Journal of Machine Tools \& Manufacture, v. 46, n. 14, pp.1854-1861, November, 2006.

[20] PETERS, J, DECNEUT, A. L'espaisseur de coupe equivalente, parameter determinate in rectification. Mechaniques Materiaux Eletricité, v. 58, n. 310, pp 22-30, 1975.

[21] OLIVEIRA, J. F. G., Análise da ação do macroefeito de dressagem de rebolos no desempenho do processo de retificação, Tese de D Sc., Universidade de São Paulo, São Carlos, SP, Brasil, pp. 272, 1988.

[22] GRAF, W., Handbook Cylindrical Grinding, Winterthur Schleiftechnik AG, Switzerland, 2010.

[23] MARINESCU, I., ROWE, W., DIMITROV, B., et al., Tribology of abrasive maching process, Nova York, Willian Andrrew Publishing, 2004.

[24] MALKIN, S., Grinding Technology: Theory and Aplications of Machining with Abrasives, 1a ed., Chichester, Ellis Horwood Limited, 1989. 
[25] TÖNSHOFF, H.K., LIERSE, T., INASAKI, I. Grinding of advanced ceramics. In: JAHANMIR, S.; RAMULU, M.; KOSHY, P. Machining of Ceramics and Composites, Marcel Dekker, Cap.3, 1999.

[26] RAVINDRA, H.V., SRINIVASSA, Y.G., KRISHNAMURTHY, R., "Acoustic emission for tool condition monitoring in metal cutting”, Wear , v. 212, n. 1, pp. 78-84, 1997.

[27] SVIRSHCHEV, V.I., VOL 'NOV, D.N., KROKHIN, A.N. Reducing the Surface Roughness in Grinding, Russian Engineering Research, v. 28, n. 5, Allerton Press, Inc., 2008.

[28] JEDRZEJEWSKI J., MODRZYCKI W. Intelligent supervision of thermal deformations in high precision machine tools, Manchester, UK, 1997.

[29] MARINESCU, I., TÖNSHOFF, H.K., INASAKI, I., Handbook of Ceramic Grinding and Polishing, New Jersey. Noyes Publications, cap.2, 1998.

[30] KING, R. I., HAHN, R. S., Handbook of modern technology. pp.119-167, 1992.

[31] BABEL, R., KOSHY, P., WEISS, M., "Acoustic emission spikes at workpiece edges in grinding: Origin and applications", International Journal of Machine Tools and Manufacture, v. 64, pp. 96-101, 2013.

[32] LIU, C. H., ADRIAN CHEN, C., CHEN, C. A., et al., "Grinding force control in an auto-matic surface finishing system”, Journal of Materials ProcessingTechnology, v. 170, pp.367-373, 2005.

[33] MINKE, E. “Contribution to the role of coolants on grinding process and work results”, Technical Paper-Society of Manufacturing Engineers, pp. 1-18, 1999. 